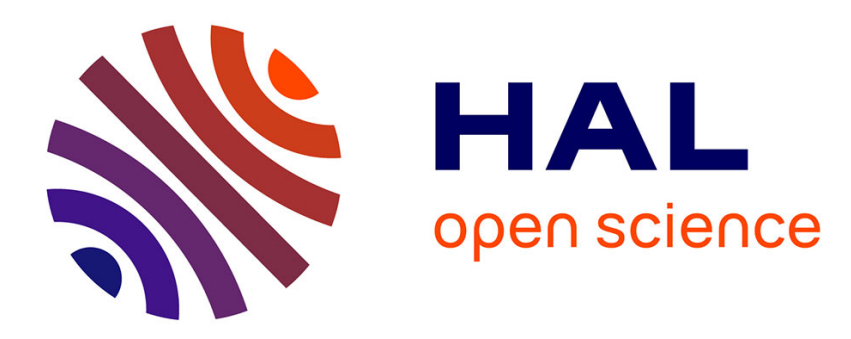

\title{
Bidimensional expressions of fractions in Chinese
}

Rémi Anicotte

\section{To cite this version:}

Rémi Anicotte. Bidimensional expressions of fractions in Chinese. Cahiers de linguistique - Asie Orientale, 2015, 44 (1), pp.36-56. 10.1163/19606028-00441p02 . hal-01191510

\section{HAL Id: hal-01191510 https://hal.science/hal-01191510}

Submitted on 2 Sep 2015

HAL is a multi-disciplinary open access archive for the deposit and dissemination of scientific research documents, whether they are published or not. The documents may come from teaching and research institutions in France or abroad, or from public or private research centers.
L'archive ouverte pluridisciplinaire HAL, est destinée au dépôt et à la diffusion de documents scientifiques de niveau recherche, publiés ou non, émanant des établissements d'enseignement et de recherche français ou étrangers, des laboratoires publics ou privés. 


\title{
Bidimensional expressions of fractions in Chinese
}

\author{
Rémi Anicotte \\ CRLAO \\ remi_anicotte@yahoo.com
}

\begin{abstract}
A generic pattern of expression for fractions accounts for numerators and denominators, thus generally producing bidimensional numerical expressions. In Qin-Han mathematical texts, fractions were constructed as predicative phrases: the monodimensional expression 'denominator's name $+f \bar{n}$ ' of a unit fraction $1 / n$ acted as subject, and the numerator's name acted as predicate. The morpheme $z h \bar{\imath}$ could be used as an optional marker of this predicative relation. Later evolutions were not linear, and reveal the effects of language planning and of free linguistic invention, finally giving rise to the inseparable fraction names of Contemporary Chinese.
\end{abstract}

\section{Keywords}

Chinese diachronic syntax - fractions - numerical expressions - separable semantic units - language planning - measure words - Suàn shù shū 《算數書》

\section{Résumé}

Un schéma générique pour dire les fractions rend compte des numérateurs et dénominateurs produisant des expressions numériques bidimensionnelles. Dans les textes mathématiques Qin-Han, elles étaient construites comme des énoncés prédicatifs où

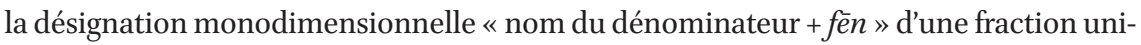
taire $1 / n$ servait de sujet et le numérateur de prédicat. Le morphème $z h \bar{\imath}$ était utilisé facultativement comme marqueur de cette relation prédicative. Les évolutions de ces expressions n'ont pas été linéaires et révèlent l'action d'inventions et de normalisations linguistiques pour aboutir aux appellations insécables des fractions en chinois contemporain. 


\section{Mots-clés}

syntaxe diachronique chinoise - fractions - expressions numériques - unités sémantiques sécables - planification linguistique - classificateurs - Suàn shù shū 《算數 書》

\section{Monodimensional and Bidimensional Expressions of Fractions in Chinese}

Historical records of fractions in Chinese are characterized by a relatively long time span of available data, starting with inscriptions on bronze vessels in the Warring States period (from the fifth century BCE until 221 BCE). However, this ancient data is limited to a few instances, making it difficult to draw a full picture of the variety of expressions used. The Qin-Han period (221 BCE-220 CE) offers quite a different situation, with several mathematical texts excavated since the 1980s. These include hundreds of instances of fractions in various syntactic contexts, providing an opportunity to understand their construction and the syntactical functions of their components. Subsequent developments are observed mainly through transmitted mathematical texts separated by gaps of a few centuries. Some developments may be related to grammatical changes, but the regularity of some texts in how fractions are expressed, compared to the variability of other corpuses, suggests deliberate language planning in the former ones even though the particulars of decision making have been lost.

Expressions for fractions can on occasion be special lexicalized items; for example Chinese texts of the Qin-Han period contain special terms for 1/3, 1/2 and $2 / 3$. But such a scheme is viable only for a few specific fractions, and a generic linguistic pattern capable of communicating a fraction numerator/denominator of any two integers has to account for both the numerator and the denominator, ${ }^{1}$ commonly yielding numerical expressions which are bidimensional; the only possible exceptions in Qin-Han Chinese are unit fractions $1 / n$ which can sometimes escape from this principle by stating only their denominator $n$, producing monodimensional expressions.

1 In Contemporary Chinese, a 'denominator' is called 'fēnmǔ 分母, with 'mǔ' 母 [mother] and 'fēn' 分 [fraction or part]; 'fènmü' can therefore be rendered as 'the mother of the fraction' (or 'the generator of the fraction', which may sound less naïve). A 'numerator' is called 'fēnzì 分子 with ' $z \grave{\imath}$ 子 [child]; 'fènzì can be rendered as 'the child of the fraction' (or 'a sub-set of the fraction'). A 'fraction' is called 'fènshù' 分數; it can be rendered as 'the number [shù 數] of parts [fèn 分].' In Qin-Han texts a 'fraction' was usually called 'fèn' 分. 
In bronze inscriptions from the Western Zhou (eleventh to eighth centuries BCE) to the Warring States period (fifth century BCE to 221 BCE) and in QinHan manuscripts, unit fractions $1 / n$ were expressed with the monodimensional $n$ fèn, and nothing could be introduced between the two components; these compounds are therefore inseparable semantic units which we can call fraction names. The earliest instances of $n$ fèn compounds are found in inscriptions on some bronze vessels; ${ }^{2}$ the oldest one dates to the end of the Western Zhou, while the others were produced during the Warring States period. There are only 15 instances of $n$ fën compounds: three instances of sän fền $1 / 3,{ }^{3} 10$ instances of sìfēn $1 / 4,{ }^{4}$ one instance of wŭfèn $1 / 5,{ }^{5}$ and one instance of liù fèn $1 / 6 .{ }^{6}$ For example, the instance in (1) is extracted from the text on the vessel known as Measurement of Shang Yang [Shāng Yāng Liàng] 商鞅量, and defines the capacity unit shēng as $161 / 5$ cùn. ${ }^{7}$ The monodimensional expression wŭ fên cùn for $1 / 5$ cùn is inserted as a subject in a predicative phrase with the integer [1] used as predicate to form wǔ fên cùn yı̆, a bidimensional expression for $1 / 5$ cùn.

2 I accessed these inscriptions through Hong Kong Chinese University's CHANT database [Hàndá Wénkù 漢達文庫]. The reference numbers of the inscriptions and the names and date ranges of the artifacts are those of the Yìn-Zhōu jïnwén jíchéng 《殷周金文集成》 (Zhōngguó shèhuì kēxuéyuàn kǎogǔ yánjiūsuǒ 1984), which underlies CHANT. Suffixes to the identification numbers of the inscriptions are additions by CHANT's editors.

3 The instances of sān fèn $1 / 3$ are found in inscriptions 2105 and 2451 (two occurrences) on the 上樂珠鼎 and 梁上官鼎 vessels respectively, both dating to the late Warring States.

4 The instances of si fên $1 / 4$ are found in inscription 1808 on the 四分鼎 vessel, in 2104 on the 上岂珠鼎 vessel, in 2481 on the 二年蜜鼎 vessel, in 2527.2 on the 卅年鼎 vessel, in 2609 on the 廿七年大梁司寇鼎 vessel, in 2764.1 (three occurrences) on the 井二年坪安君鼎 vessel and in 2793.1 on the 坪安君鼎 vessel, all dating to the late Warring States. There is also one instance in inscription 2577 on the 十七年平陰鼎蓋 vessel dating to the Warring States, though with no indication as to whether it is from the early or late period.

5 The instance of wǔ fên $1 / 5$ is found in inscription 10372 on the 商鞅量 vessel dating to the Warring States.

6 The instance of liù fên 1/6 is found in inscription 683 on the 虢季氏子段鬲 vessel dating to the late Western Zhou, which was in power until the eighth century вСЕ; it is the oldest piece cited here.

7 This was described by Li Yan (1998[1954]:16). Shang Yang 商鞅 (c. 390-338 BCE) was a reformer of the Kingdom of Qin. 


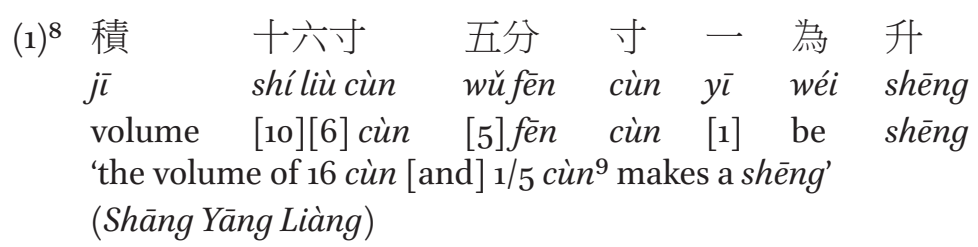

On one inscription, fēn is associated with bàn 半 and shăobàn 少半 to form the compounds bàn fên and shăobàn fēn:10 they likely mean the exact values $1 / 2$ and $1 / 3$ respectively since they were commonly used (without fèn) within exact calculations in Qin-Han manuscripts.

Now an expression for the non-unit fraction 2/3 found in the Analects of Confucius [Lúnyǔ] 《論語》, a transmitted corpus dating to the late Warring States period, is given in (2). The compound [3] fèn, a monodimensional expression for the unit fraction $1 / 3$, is inserted in a noun phrase as the modifier of tiānxià 天下 [the world] to express 'one third of the world'; this phrase is in turn inserted into an existential construction with the verb yoru 有 to state that two such parts of one third are being considered. Eventually the fraction $2 / 3$ is expressed in a way which can be paraphrased as 'two of the thirds of the world' and no inseparable number name for $2 / 3$ is involved.

(2) 三分 sān fēn
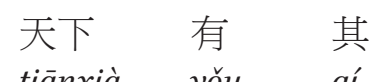

[3] fèn

tiānxià

yǒu

qí

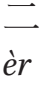

'two thirds of the world' (approximate value)

(Lúnyǔ - Tài Bó 《論語·泰伯》)

The following abbreviations have been used in this paper: CLF: classifier; CoP: copula; DECL: declarative; DEM: demonstrative; FUT: future; LOC: locative; MW: measure word; Num: numeral; PART: particle; 1 SG: first person singular pronoun; 3 OBJ: third person object pronoun; 3 POSS: third person possessive pronoun; $[n]$ (with a number $n$ written in Arabic digits): the mono-morphemic expression of the number $n$ in a given language; and $A(B)$ and $A(B C)$ : the character $A$ is a rendition of the original character encountered in the Chinese corpus, the character $\mathrm{B}$ or the sequence $\mathrm{BC}$ in parenthesis is a modern form of what is understood for A. For example: 參 (三), 廿 (二十), 井 (三十).

9 Normally in English we would simply write $161 / 5$ cùn and say 'sixteen and one-fifth of a cùn.' My translation emphasizes the repetition of the measure word in the original. One occurrence of each compound is found in inscription 10440.b on the 十四兩銀俑 vessel dating to the Warring States. 
The morpheme fên 分 could be used as a verb meaning 'to split' or 'to share', or as a noun meaning a 'part' or a 'fraction'.11 However, it seems reasonable to assume that fên in $n$ fên was already fossilized and that the interpretations as noun or verb were likely already neutralized within those compounds. If we try to reconstruct the origin of $n$ fèn, we can rationalize it as 'adverb + verb' which indicates the manner of the partitioning, or as 'subject + verb' stating which quantity divides. It can also be construed as 'Num + noun'. From a semantic point of view, the question is whether fên referred more to the action of partitioning or more to the result (the parts) of this action. All of these analyses are consistent and non-contradictory; each could well have reinforced the others to establish this expression.

The Suàn shù shū 《算數書》 is a mathematical text written on some 190 bamboo strips (some are damaged and some may have been lost). It is approximately 7,000 characters long. The manuscript was excavated during the winter of 1983-1984 from a Han dynasty tomb where a calendar for the year 186 BCE was found; the tomb is thus thought to have been closed that very year and the manuscript was probably written in the beginning of the second century вСЕ. Peng Hao (2001:4-6) states that the production and taxation standards mentioned on various occasions in the manuscript prove that some parts were copied from texts originally written in the Kingdom of Qin before the unification of China in $221 \mathrm{BCE}$, while other texts could only have been composed during the reign of the Western Han dynasty, which began in 206 вСЕ.

In this corpus, there are 301 occurrences (not all different) of expressions for fractions: 83 instances of monodimensional expressions for unit fractions, 143 of bidimensional expressions for unit or non-unit fractions, and 75 of lexicalized terms. ${ }^{12}$ That is to say this corpus exhibits many more instances of fractions than Qin-Han manuscripts that are not specialized in mathematics.

The reading of this term when it is a verb is rightfully fèn, when it is a noun it should arguably be read fèn with a falling tone regardless of the modern reading fên. Note that in the commentaries added to the Nine Chapters [Jiǔ zhāng suàn shù] 《九章算術》during the seventh century CE, fên is used on occasion to designate the decimal rank 1/10, in other texts it was $1 / 100$; this was not the case in Qin-Han texts. 
Those contain but a few scarce expressions ${ }^{13}$ and would not allow for a significant mapping of their variety. For example, Zhang Shoujun (1997) and Fang Wenyi $(1995,2009)$ who referred to the work of Yang Shuda $\left(1885^{-1956)}\right.$, and Da Zhengyue \& Yin Shunmin (2008) all gathered scattered examples expressing fractions found in transmitted Chinese texts. Hu Changqing (1996) also used data from excavated texts. They did not have the opportunity to work on excavated texts of mathematics and therefore did not have enough data to correlate the various patterns of expressions with the context of syntactic insertion. Other Qin-Han manuscripts of mathematics were discovered more recently. A first $\operatorname{scan}^{14}$ shows no discrepancy concerning the expression of integers and fractions; therefore the study of the Suàn shù shū makes it possible to draw a reliable picture of the linguistic expressions for fractions during the Qin-Han period. Fractions in these texts were all proper fractions, that is to say smaller than one, with the denominator being larger than the numerator. They were all written in the Chinese language; I use Arabic numerals in translations because they are easier to read than numbers written out in English, but there was no symbolic numerical notation in the originals.

There are 83 instances (not all different) of monodimensional expressions of unit fractions $1 / n$ in the text. Among them, 76 do not involve a measure word, for example sì fèn for $1 / 4$ in (3), while eight instances do, for example wǔ fèn cùn for $1 / 5$ cùn in (4). Measure words follow $n$ fên $n$ in the same way they can follow integers, that is to say $n$ fèn was a numeral in its own right. However, omitting the name of the numerator [1] in the expression of a unit fraction was not obligatory, and there were 46 instances (not all different) of bidimensional expressions for unit fractions stating both the numerator as [1] and the denominator's name. The numerator's name [1] was usually omitted when the fraction was a factor in a multiplication: see shaded $\emptyset$ in (3) with no measure word, and in (4) with measure words. But [1] was used when stating the result: see shaded $y \bar{\imath}-[1]^{15}$ in (3) and (4) where we can analyze the construction as a predicative clause with the monodimensional name of the unit fraction acting

13 Hu Changqing (1996) could find only 12 bidimensional expressions of fractions in the Qin manuscripts (none concerned with mathematics) excavated in 1975 at Shuihudi. The survey ended up with only 49 instances, mostly from transmitted sources.

I checked Shù 《數》(it belonged to the Yuèlù Academy, and the text is available in Xiao Can 2010) and Suànshù 《算術》(excavated in 2006 at Shuihudi; at the time of my research, only short excerpts were available in Chen Lixin 2008 and in Chemla \& Ma Biao 2011).

According to the rules of pinyin transcription, the digit [1] is always romanized as $y \bar{\imath}$ with the first tone mark, regardless of the actual tone in Contemporary Chinese, which depends on the tone of the following syllable. 
as the subject and the number name [1] acting as the predicate. ${ }^{16} \operatorname{In}(4)$ and (5), the measure words inserted right after fên are modified by the unit fraction names; the resulting noun phrases 'denominator's name + fèn $+\mathrm{MW}$ ' are subjects of $[1]$.

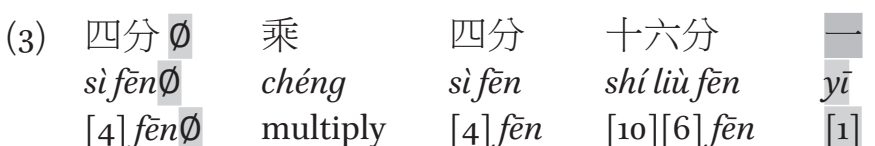

' $1 / 4$ times $1 / 4$ is $1 / 16$ '

(Suàn shù shū, strip 9)

$\begin{array}{llll}\text { (4) 五分 } & \text { 寸 } \varnothing & \text { 乘 } & \text { 尺 } \\ \text { wúfēn } & \text { cùn } \varnothing & \text { chéng } & \text { chŭ } \\ \text { [5]fèn } & \text { cùn } \emptyset & \text { multiply } & \text { chı̆ }\end{array}$

\begin{tabular}{|c|c|c|}
\hline & 尺 & 一 \\
\hline ¿ shifèn & chŭ & $\overline{y \bar{\imath}}$ \\
\hline [5][10] fèn & ch̆̆ & {$[1]$} \\
\hline
\end{tabular}

' $1 / 5$ cùn times chŭ is $1 / 50$ [square] chù' (note that 1 cùn $=1 / 10$ chĭ and that the difference between length and surface units is not explicit in the original text)

(Suàn shù shū, strip 4)

\begin{tabular}{|c|c|c|c|}
\hline 粺米 & 四分 & 升 & 方 \\
\hline bài mǔ & sìfēn & shēng & $z h \bar{\imath}$ \\
\hline milled millet & [4] fèn & shēng & $z h \bar{\imath}$ \\
\hline
\end{tabular}

Now there are 97 instances (not all different) of bidimensional expressions of non-unit fractions, as in (6)-(9). They were also built as predicative phrases by putting the numerator's name in the predicate position and inserting the monodimensional names of unit fractions 'denominator's name + fền' as subjects without a measure word in (6) and (8), and with a measure word right after fên in (7) and (9).

16 This is the same construction as in (1) dating to the Warring States. 
(6) 五分 二

wǔfèn èr

[5] fèn [2]

' $2 / 5$ '

(Suàn shù shū, strip 22)

(7) 二 錢

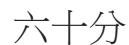

錢

五十七

èr qián

liù shífēn

qián

wǔ shíqī

[2] qián

[6][10] fèn

qián

[5][10][7]

'2 qián 57/6o qián' (i.e. 2 57/60 qián) ${ }^{17}$

(Suàn shù shū, strip 23)

(8)

$\begin{array}{lllll}\text { 各 } & \text { 受 } & \text { 井(三十) 分 } & \text { 之 } & \text { 廿(二十) 三 } \\ \text { gè } & \text { shòu } & \text { sānshífèn } & \text { zhì } & \text { èr shísān } \\ \text { each } & \text { get } & {[3][10] \text { fèn }} & z h \bar{\imath} & {[2][10][3]}\end{array}$

'each gets 23/30'

(Suàn shù shü, strip 26)

(9) 米

$m \check{r}$
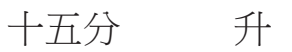

之

四

husked millet [10][5] fèn shēng

$z h \bar{\imath} \quad s \grave{\imath}$

'4/15 shēng of husked grain'

(Suàn shù shū, strip 98)

The total of 143 instances of bidimensional expressions for unit and non-unit fractions in the corpus are distributed between four patterns defined by whether or not the item $z h \bar{\imath}$ is used and whether or not a measure word is involved. We have the following distribution:

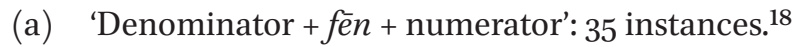

(b) 'Denominator + fēn $+\mathrm{MW}+$ numerator': 54 instances. ${ }^{19}$

17 The fraction $57 / 60$ is inserted in a mixed number with the integer 2 ; this is common in Qin-Han mathematical texts. The two numbers are expressed with two independent quantification phrases which are juxtaposed here, and are concatenated with the conjunction yòu in other instances. The measure word occurred first with the integer and was usually repeated after fên. My translation highlights this repetition.

18 See, for example (3) and (6).

19 See, for example (4) and (7). 
(c) 'Denominator $+f \bar{e} n+z h \bar{\imath}+$ numerator': 7 instances. $^{20}$

(d) 'Denominator $+f e \bar{n}+\mathrm{MW}+z h \bar{\imath}+$ numerator': 47 instances. $^{21}$

This mapping is shown again in Table 1.

TABLE 1 Bidimensional expressions of fractions in the Suàn shù shü: The item zhì and its insertion with measure words

\begin{tabular}{llll}
\hline & $\boldsymbol{z h} \overline{\boldsymbol{\imath}}-$ & $\boldsymbol{z h \overline { \boldsymbol { \imath } } +}$ & \\
\hline $\mathrm{MW}-$ & (a) 35 & (c) 7 & 42 \\
$\mathrm{MW}+$ & (b) 54 & (d) 47 & 101 \\
& 89 & 54 & 143 \\
\hline
\end{tabular}

The item $z h \bar{\imath}$ is never used with the monodimensional expressions of unit fractions, it occurs only in bidimensional expressions of unit and non-unit fractions followed by the numerator's name. Extrapolating from the mapping above, ${ }^{22}$ it is possible to explain the way it was used in terms of general trends:

(i) The item zhi occurred only in bidimensional expressions of fractions before the numerator's name.

(ii) The item $z h \bar{\imath}$ was seldom employed when no measure word was present.

(iii) The item zhi was not obligatory even when there was a measure word.

Purely textual facts are enough to reveal these characteristics of the construction regardless of any definitive syntactical interpretation of $z h \bar{l}$. It is nevertheless legitimate to construe $z h \bar{\imath}$ as an anaphoric item referring to the segment 'denominator + fèn $(+\mathrm{MW})$ ' which is inserted as the subject of a predicative phrase, the predicate being the numerator. An alternative interpretation is to

20 See, for example (8) with a non-unit fraction. There is no instance of this pattern in the Suàn shù shū for a unit fraction, but [3][10] fên zhī [1] is found on strip 0778 of Shù (Xiao Can 2010:51).

$21 \quad$ See, for example (5) and (9).

22 Hu Changqing (1996) had a sample of 49 instances, which was too small to reveal the relationships between the variations of the sequences ' $\mathrm{Num}_{1}+f \bar{e} n(+\mathrm{MW})(+z h \bar{\imath})+\mathrm{Num}_{2}$ '

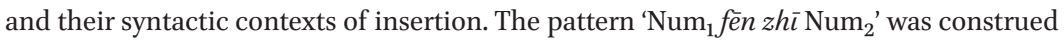
as a concatenation of ' $\mathrm{Num}_{1}$ fèn $\mathrm{Num}_{2}$ ' and 'Num $\mathrm{Nh}_{1} \mathrm{Num}_{2}$ ' (this latter construction is exemplified in Section 3); this approach was purely formal and missed the role of syntax on the shape of the separable expression. 
consider zhi as a marker of nominal determination used optionally to insert the 'denominator + fên' names of unit fractions as modifiers in noun phrases, thus putting the numerator's name in the head position. ${ }^{23}$ Those two analyses are individually consistent, not mutually incompatible; they are nevertheless just rationalizations. We can simply claim that zhi can be optionally added as a marker of a predicative relation.

Back to purely textual facts, it can be observed that the use of $z h \bar{\imath}$ inside the bidimensional expression of a fraction was correlated with the syntactic insertion of this fraction. First, among all the bidimensional expressions of unit fractions, all of those which use $z h \bar{\imath}$, and only these, are in a predicative position after a mass noun. This also applies to the bidimensional expressions of non-unit fractions, but not as a yes-or-no rule, and actually one instance is placed after a phrase ${ }^{24}$ rather than a noun. Moreover, among only four instances where $z h \bar{\imath}$ is used in expressions for fractions which are not placed after a noun or a phrase, two are objects of a verb. Table 2 shows the situation merging the insertion contexts as predicates or objects:

TABLE 2 Bidimensional expressions of fractions in the Suàn shù shü: The item zhì and the insertion of fractions as dependent clauses

\begin{tabular}{lccc}
\hline & $\boldsymbol{z h} \boldsymbol{h}-\boldsymbol{z h} \mathbf{+}$ & \\
\hline Inserted - & 76 & 2 & 78 \\
Inserted + & 13 & 51 & 64 \\
& 89 & 53 & $142^{25}$ \\
\hline
\end{tabular}

There are 78 instances categorized in Table 2 as not inserted. They are found in calculations as in (3) and (4) above. The occurrence rate of $z h \bar{\imath}$ when the fraction is inserted amounts to $51 / 64 \times 100 \approx 80 \%$. Conversely the occurrence rate of configurations without $z h \bar{\imath}$ is $76 / 89 \times 100 \approx 85 \%$ when the fraction is not in-

23 This analysis is actually the only one consistent with the pattern 'denominator's name + $z h \bar{\imath}+$ numerator's name' (without fèn) found on occasion (not in the Suàn shù shü) to express fractions. Quantification phrases using the quantifier as head of a noun phrase are quite common in the world's languages; e.g. in English: 'two fifths of the population', where the numeral 'two fifths' is in head position.

24 It is the instance on strip 20 placed after the phrase $y u \bar{e} z h \bar{\imath}$ 約之 (meaning 'reduce it'), and it expresses the result of the fraction reduction.

25 The characters placed before the fraction in an instance on strip 183 are illegible, so it is not counted here and the grand total in Table 2 is only 142 and not 143 as in Table 1. 
serted as a predicate or an object; this allows us to state one more trend concerning $z h \bar{\imath}$ in expressions of fractions:

(iv) The use of $z h \grave{\imath}$ inside bidimensional fraction expressions was directly correlated with the insertion of these expressions as a dependent clause used as the predicate of a quantification phrase or as the object of a verb.

\section{Other Expressions of Fractions and Developments after the Qin-Han Period}

There were alternative bidimensional expressions of fractions other than the sequences with obligatory fèn and optional zhi found in Qin-Han mathematical texts. They were listed by Hu Changqing (1996), Zhang Shoujun (1997), Fang Wenyi $(1995,2009)$ and Da Zhengyue \& Yin Shunmin (2008).

The pattern 'Num $1+z h \bar{\imath}+\mathrm{Num}_{2}$ ', without the morpheme fèn and with $\mathrm{Num}_{1}$ being larger than $\mathrm{Num}_{2}$, was not used in Qin-Han mathematical texts but is found in numerous other texts to express the fraction $\mathrm{Num}_{2} / \mathrm{Num}_{1}$. It was the general pattern to express a fraction when no measure word was involved in the Tóng wén suàn zhı̌ 《同文算指》(1613) and in some nineteenth century mathematical books. ${ }^{26}$

'Num $1+f e \bar{n}+\operatorname{verb}(+q i ́)+\mathrm{Num}_{2}$ ' sequences are found in several texts. The item qi 其 is a third person possessive pronoun. The verb can be yǒu 有 (have, possess) as in (2). Hu Changqing (1996) reported an expression given in (10)

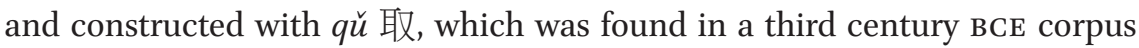
excavated in 1975 at Shuihudi; Xiao Congli (2006) mentioned an instance - given in (11) - with y̌ 以 from an excavated first century CE manuscript; Tian Youcheng \& Zeng Luping (2000) gave an expression with xiàng 向 (towards, go towards) reproduced in (12) from a sixth century Buddhist text.

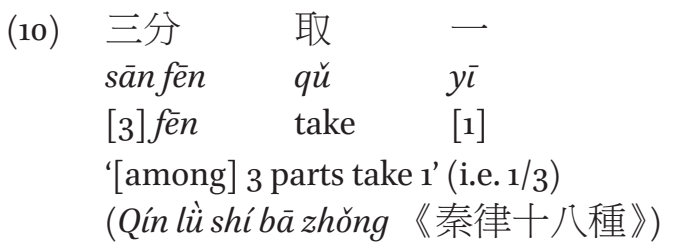

26 This pattern can still be used in Contemporary Chinese but usually to state the order rank in a finite set, e.g. [9] $z h \bar{\imath}[7]$ can label the seventh element in an ordered set of nine elements. 
(11) 畜

chù

參 (三) 分 以

以

其

qí

$y \bar{\imath}$

cattle

[3] fèn

take

${ }_{3} \mathrm{POSS}$

$[1]$

'take 1 of the 3 parts of the cattle' (i.e. ' $1 / 3$ of the cattle') (Jüyán Xinjiăn 《居延新簡》 7707: E.P.F22:228)

(12)

$\begin{array}{lll}\text { 三分 } & \text { 向 } & \text { 二 } \\ \text { sānfén } & \text { xiàng } & \text { èr } \\ \text { [3]fēn } & \text { towards } & {[2]} \\ \text { '2/3' } & & \\ \text { (Dàzàngjìng } & \text { 《大藏經》) }\end{array}$

The juxtaposition 'Num $1+\mathrm{Num}_{2}$ ' of two monosyllabic numerals, the first one being larger than the second one, ${ }^{27}$ is found on occasion (not in the Suàn shù $s h \bar{u}$ ) to express the fraction $\mathrm{Num}_{2} / \mathrm{Num}_{1}$. With two digits it is unambiguous; for example the expression [9][1] is a common designation of an ancient tax system for one ninth of the crop. But a sequence ' $\mathrm{Num}_{1}+\mathrm{Num}_{2}$ ' surely becomes ambiguous if the first numeral is the name of a decimal rank: for example $1 / 10$ expressed as [10][1] is indistinguishable from the name of the integer $11 .^{28}$

The existence of all these forms means that the expressions of fractions in Qin-Han manuscripts of mathematics was not known or accepted by all. Generic linguistic expressions of fractions probably emerged together with the conceptual extension of the realm of numbers, which came to encompass fractions of any two integers. The earliest expressions were likely produced freely. The standardization of these expressions could only come later and was likely initiated by scholars and then forced on the next generation by educators. The shift from freely coined phrases to approved and standardized expressions reflects a transition from a time of spontaneous linguistic creation to what Haugen (1983) calls 'corpus planning'. He distinguished four steps: selection of norm (which is societal and exterior to the language); codification of norm; implementation of function (includes the activities of writers and institu-

27 A juxtaposition of two digits with the first one smaller than the second one is the expression of the product of the said two digits, as when reciting the multiplication table. The number meant is usually stated after the juxtaposition of digits, e.g. [7][8] [5][10][6] expresses $5^{6}$ as the product 7 times 8 . Phrases of this type have always been quite common.

28 The expression 'wàn y $y \vec{\imath}\left[10^{4}\right][1]$ ended up lexicalized and is now used to mean 'by any chance'. It cannot be confused with the name of an integer since the Contemporary Chinese name for 10,001 is [1] [104] ling [1]. 
tions); and elaboration of function (involves the production of a linguistic corpus complying with the norm). In Chinese, the competing candidates for the status of a norm were expressions using fên or zhī alone, or associating both fền and $z h \bar{\imath}$.

The Qin-Han 'Num + fên $(+\mathrm{MW})(+z h \bar{\imath})+\mathrm{Num}_{2}$ ' sequence was the mainstream model in mathematical texts until the thirteenth century. It was used in the Nine Chapters. This classic of mathematics was originally written during the Han dynasty (206 вСЕ-220 CE) and belonged to the same tradition as the Suàn shù shū. The known edition was prepared in the seventh century CE. All bidimensional expressions for fractions included $z h \bar{\imath}$ and measure words were inserted between 'denominator's name + fên' and ' $z h \vec{\imath} .{ }^{29}$ We definitely lack information to establish whether this shift from optional to compulsory zhi was decided by the Han dynasty editor of the Nine Chapters or if it was an innovation of the seventh century editors.

The Song dynasty mathematician Qin Jiushao, in his Shù shū jiǔ zhāng ${ }^{30}$ (1247), used the same expressions for fractions as the Nine Chapters. But Li Zhizao's Tóng wén suàn zhǔ (1613) $)^{31}$ exhibits a particular dichotomy: when there was a measure word, it was inserted between fèn and $z h \bar{\imath}$, as in the expression of 2130/4004 in (13), following the pattern of the Nine Chapters and Qin Jiushao; but when no measure word was involved, the sequence 'denominator's name + $z h \bar{\imath}+$ numerator's name' (without fên) was used, as for $1065 / 2002$ in (13). ${ }^{32}$

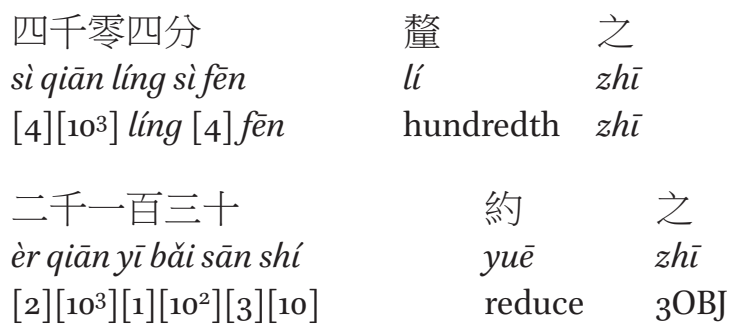

29 I refer to Guo Shuchun (2002) for this observation, and to Chemla \& Guo Shuchun (2004:43-46) for the history of the Nine Chapters.

30 Qin Jiushao 秦九韶 (1202-1261) published the Shù shū jiǔ zhāng《數書九章》 in 1247 during the Southern Song dynasty; I used the edition from 1842.

31 The Tóng wén suàn zhì (1613) was written by Li Zhizao 李之藻 (1565-1630), with plausible participation by Xu Guangqi 徐光啟 (1562-1633) and Matteo Ricci (1552-1610). I used the Si kù quán shü 《四庫全書》edition prepared in the eighteenth century.

32 There is another dichotomy between the expression of 4004 with the linking term ling and the expression of 2002 without ling. The former follows Qin Jiushao's pattern for integer names, whereas the latter follows the Nine Chapters. See Anicotte (2015) for more details about the names of integers in Chinese. 


$\begin{array}{llll}\text { 乃 } & \text { 二千二 } & \text { 之 } & \text { 一千六十五 } \\ \text { năi } & \text { èr qiān èr } & \text { zhì } & \text { yīqiān liù shíwǔ } \\ \text { then } & {[2]\left[10^{3}\right][2]} & z h \bar{\imath} & {[1]\left[10^{3}\right][6][10][5]} \\ \text { 'reduce 2130/4004 hundredths }{ }^{33} \text { to get 1065/2002 [hundredths]' } 34 \\ \text { (Tóng wén suàn zhǔ, vol. 1, p. 8) }\end{array}$

In the mathematics books of the Báifú táng suàn xué cóng shū collection ${ }^{35}$ edited from 1872 to 1877 during the Qing dynasty, some authors like Wu Jiashan ${ }^{36}$ used Li Zhizao's system of expression whereas others like Shi Yuechun ${ }^{37}$ used Nine Chapters' and Qin Jiushao's systems, possibly in an attempt to revive the Song dynasty tradition of mathematics. ${ }^{38}$

The situation in Contemporary Chinese is quite different. For example, the fraction $2 / 5$ is said '[5] fên zhi [2]' and nothing can be introduced between the components; that is to say, the compound 'fên zht has been fossilized and the expression is inseparable. This advent of inseparable expressions for fractions reflects no conceptual advancement, just a linguistic change likely provoked by language planning during the late nineteenth or early twentieth centuries. Bréard (2001, 2004) already outlined some processes yielding today's Chinese language for mathematics, but - to my knowledge - more research on textbooks and discussions of education is called for to determine what authority designed and implemented the standard number names of Contemporary Chinese.

33 In the Tóng wén suàn zhŭ, decimal values were expressed using a scale starting with the words fēn 分 for $10^{-1}$, li 嶅 for $10^{-2}$, háo 毫 for $10^{-3}$, sī 絲 for $10^{-4}$, hu 忽 for $10^{-5}$, wēi 微 for $10^{-6}$; for each digit after the decimal, the value was specified. For example, 0.123 would be said [1] fên [2] lí [3] háo. The pattern 'Num + value' followed the one used with units of measurement.

34 The result is subsequently expressed as 0.0053196; the expression of decimal numbers in Chinese is beyond the scope of this paper.

35 The Bái fú táng suàn xué cóng shū 《白芙堂算學叢書》collection is composed of 23 books of mathematics edited by Ding Quzhong 丁取忠 (1810-1877); more details can be found in Wu Wenjun (2000:200-203).

36 Wu Jiashan 吳嘉善 (1818-1885) wrote Suàn xué èr shíyīzhǒng 《算學二十一種》(1863); I referred to the edition from 1874 .

37 Shi Yuechun 时曰醇 (1807-1880) wrote Băi jī shù yăn 《百鸡术衍》(1861); I referred to the edition from 1872 .

38 The fourteenth century saw developments in calculations with an abacus and lost interest in some domains of mathematics explored earlier and related to calculations with counting rods. Chinese mathematicians regained interest in Qin Jiushao's work only after the introduction of Western mathematics in the sixteenth and seventeenth centuries. 
In Qin-Han mathematical texts, bidimensional expressions for fractions were not inseparable number names, and when a measure word was involved it was inserted right after 'denominator's name fèn', yielding, for example in (5), the clause '[4] fèn MW zhì [1]'.

Now in Contemporary Chinese, the compound '[4] fèn zhī [1]' in (14) is inseparable and is inserted directly before a measure word.

$\begin{array}{llll}\text { (14) 四分 } & \text { 之 } & \text { 一 } & \text { 升 } \\ \text { sifēn } & z h \bar{\imath} & y \bar{\imath} & \text { shēng } \\ \text { [4]fèn } & \text { zhì } & {[1]} & \text { shèng } \\ 1 / 4[\text { of a] liter' } & & \end{array}$

The relocation of the measure word from between 'fêen' and ' $z h \vec{\imath}$ to after the sequence 'fēn $z h \vec{\imath}$ was sustainable because it was compatible with Chinese syntax. The gradual generalization of classifiers was complete around the thirteenth century ${ }^{39}$ and made the sequence 'Num + CLF' more frequent; this pattern was then readily available to be used by analogy to produce 'fraction name + MW' ${ }^{40}$ This does not mean that the position shift was triggered by syntactic evolution; the variability of the expressions in nineteenth century texts implies that it was rather the result of corpus planning.

Contemporary Chinese inseparable fraction names can be inserted directly before nouns as in (15), but it is also possible to insert the nominal determination particle de 的 after the fraction name, as in (17).

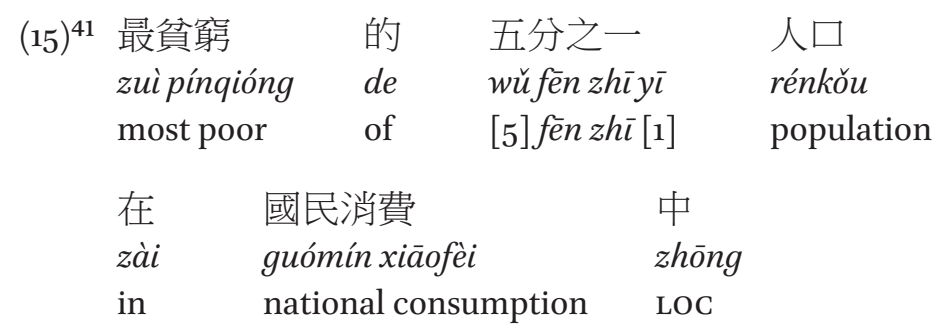

39 Peyraube \& Wiebusch (1993), Peyraube (1998).

40 Only the order within the construction 'Num + CLF' is relevant, not the position of a quantified noun with respect to this segment. 


所占 份額
suǒzhàn fenné
PART occupy portion
'the portion of national consumption constituted by the poorest one-
fifth of the population'

The fact that Contemporary Chinese fraction names can be inserted before measurement units or even nouns does not rule out the possibility of using them as the head of a noun phrase built with the determination particle $d e$ 的 as in (16)-(17), or without as in (18)-(19).

\begin{tabular}{|c|c|c|c|c|}
\hline $\begin{array}{r}(16)^{42} \text { 我 } \\
\text { wǒ } \\
1 S G\end{array}$ & $\begin{array}{l}\text { 每 } \\
m e ̌ i \\
\text { each }\end{array}$ & $\begin{array}{l}\text { 小時 } \\
\text { xiǎoshí } \\
\text { hour }\end{array}$ & \multicolumn{2}{|c|}{$\begin{array}{l}\text { 粉刷 } \\
\text { fěnshuā } \\
\text { paint }\end{array}$} \\
\hline 這 & 面 & 牆 & 的 & $1 / 5$ \\
\hline zhè & miàn & qiáng & de & wǔfèn $z h \grave{\imath} y \bar{\imath}$ \\
\hline DEM & CLF & wall & of & [5] fền $z h \bar{\imath}[1]$ \\
\hline
\end{tabular}

'each hour I paint $1 / 5$ of the wall'

$(17)^{43} 1 / 5$ wǔfềnzhīyì de sìfèn zhì ȳi

[5] fèn $z h \bar{\imath}[1] \quad$ of [4] fèn $z h \bar{\imath}[1]$

' $1 / 5$ of $1 / 4$ ' (i.e. the product of two fractions)

$(18)^{44}$ 青島

Qingdăo

Qingdao

都是

dōu shi

all COP

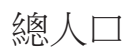

zǒng rénkǒu

total population

老年人

lǎonián rén

old person

'one-fifth of the population of Qingdao are elderly people'

41 From http://www.un.org/chinese/millenniumgoals/unsystem/indicator3.htm on the United Nations website (accessed May 18, 2014); the original was in simplified characters.

42 This example was taken from the textbook Xiăoxué Shùxué Liù Niánjí Shàng Cè 《小学 数学六年级上册》 [Sixth Grade Textbook of Mathematics - First Book] (2006:10) published in Beijing; the original text was in simplified characters.

43 Ibid.

44 This example was taken from the online newspaper http://news.bandao.cn (accessed July 15, 2013). The original text was in simplified characters. 


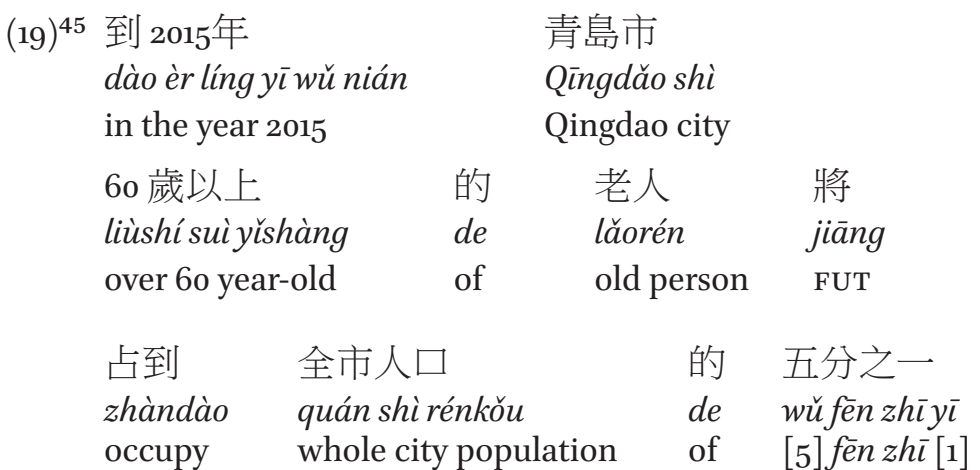

'in 2015, in Qingdao elderly people over 60 years old will make up onefifth of the population of the whole city'

Putting the noun or the fraction in the head position only changes the focus of the noun phrase and the choice is related to the insertion of this noun phrase in a sentence. Compare for example the position of the noun rénkǒu (population) with regards to the fraction name in (15) and (19).

\section{Conclusion}

A generic pattern used to express fractions needs to deal with the numerator and the denominator one way or another, thus generally yielding bidimensional numerical phrases.

In Qin-Han mathematical texts, these expressions were predicative clauses with the inseparable monodimensional $n$ fén name of a unit fraction $1 / n$ acting as subject and the numerator's name placed after it in predicative position. The morpheme $z h \bar{\imath}$ could optionally be added especially when the expression was a dependent clause inserted as a predicate or object. If a measure word was involved, it was put right after fèn. In the Nine Chapters the item zhi had become compulsory even though no syntactic change had made it necessary; this norm was still used by thirteenth century mathematician Qin Jiushao. But when no measure word was involved, the pattern 'denominator's name $+z h \bar{\imath}+$ numerator's name' was concurrently used outside of mathematical texts during the Qin-Han period and in mathematical texts at least from the seventeenth to late nineteenth centuries. Then some language planning produced Contemporary Chinese's inseparable 'denominator's name + fèn zhì + numerator's name' construction with the fossilized compound fèn zhī which is unlikely to be found outside fraction names and has turned into a lexical marker. 
Measure words are placed directly after these fraction names which behave in the same manner as integer names. They can be used indifferently in the head or modifier positions of noun phrases.

The concurrent existence of multiple forms at a given time hints at an absence of corpus planning and a time of free linguistic innovation, whereas some sudden changes are signs of decision making by some authority or authors.

\section{Acknowledgements}

For their invaluable encouragement and help with the analysis of the data, the author would like to thank Karine Chemla (SPHERE), Redouane Djamouri (CRLAO), Christoph Harbsmeier (University of Oslo), Xu Dan (INaLCO, IUf) and the reviewers of Cahiers de linguistique - Asie orientale.

\section{References}

Anicotte, Rémi. 2015. Chinese names for integers. In: Xu Dan \& Jingqi Fu (eds.). Space and Quantification in Languages of China. Berlin: Springer, 117-138.

Anicotte, Rémi. Forthcoming. Fractions in the Suàn Shù Shü (China, beginning of the 2nd century BCE). Journal of Chinese Linguistics (Hong Kong).

Bàndǎo Xīnwén 半岛新闻. Online newspaper. Accessed July 15, 2013. http://news.bandao.cn.

Bréard, Andrea. 2001. On Mathematical terminology: Culture crossing in 19th century China. In: Michael Lackner, Iwo Amelung \& Joachim Kurtz (eds.). New terms for new ideas: Western knowledge and lexical change in late imperial China. Leiden: Brill, 305-326.

Bréard, Andrea. 2004. La traduction d'ouvrages de mathématiques en Chine à la fin du xixe siècle: un processus d'introduction et d'intégration. In: Pascal Crozet \& Annick Horiuchi (eds.). Traduire, transposer, naturaliser : la formation d'une langue scientifique moderne hors des frontières de l'Europe au XIXe siècle. Paris: L'Harmattan, 123-146.

CHANT (CHinese ANcient Texts) Database [Hàndá Wénkù] 漢達文庫. Online corpus. Hong Kong Chinese University. Accessed 2011-2014. http://www.chant.org/.

Chemla, Karine 林力娜 \& Guo Shuchun 郭書春. 2004. Les Neuf chapitres : Le classique mathématique de la Chine ancienne et ses commentaires (édition critique bilingue chinois-français). Paris: Dunod. 
Chemla, Karine \& Ma Biao. 2011. Interpreting a newly discovered mathematical document written at the beginning of the Han dynasty in China (before 157 BCE) and excavated from tomb M77 at Shuihudi (睡虎地). SCIAMVs: Sources and Commentaries in Exact Sciences (Kyoto) 12. 159-191.

Chen Lixin 陳丽新 (ed.). 2008. Húběi Yúnmèng Shuihǔdì M77 fājué jiăn bào 湖北云 梦睡虎地 M77 发掘简报 [A preliminary report of the excavation at the Shuihudi tomb M77 in Yunmeng, Hubei].Jiānghàn kăogǔ 《江汉考古》 [Jianghan Archaeology] (Wuhan) 4. 31-37.

Da Zhengyue 達正岳 \& Yin Shunmin 尹順民. 2008. Lún Yǔ shùliàng cí fēnxī《论 语》数量词分析 [Numerals in the Analects of Confucius]. Gānsù gāo shī xuébào 《甘肃高师学报》 [Journal of Gansu Normal Colleges] (Lanzhou) 18(4).36-38, 45 .

Dauben, Joseph W. 2008. Suan shushu. A book on numbers and computations. Translated from the Chinese and with commentary. Archive for History of Exact Sciences 62(2). 91-178.

Fang Wenyi 方文一. 1995. Zhōngguó gǔdài wánbèi wánměi de fēnshù biǎodá xíngshì 中国古代完备完美的分数表达形式 [The perfect and complete forms for the expression of fractions in ancient China]. Zhèjiāng Shïfàn Dàxué Xuébào (Shèhuì Kēxué Băn) 《浙江师范大学学报 (社会科学版)》[Journal of Zhejiang Normal University (Social Sciences)] (Hangzhou). 1995(1). 72-78.

Fang Wenyi 方文一. 2009. Gǔ hànyǔ fēnshù biăoshì fă de géshì 古汉语分数表示法 的格式 [Forms for expressing fractions in ancient Chinese]. Zhèjiāng Shïfàn Dàxué Xuébào (Shèhui Kēxué Băn) 《浙江师范大学学报 (社会科学版)》[Journal of Zhejiang Normal University (Social Sciences)] (Hangzhou). 34(5). 61-64.

Guo Shuchun 郭書春. 2002. Shìlùn Suàn shù shū de lǐlùn gòngxiàn yǔ biānzuăn 試論《算數書》的理論貢獻與編纂 [Preliminary discussion on the theoretical contribution and compilation of the Suàn shùshū].Făguóhànxué 《法國漢學》[Sinologie Française] (Beijing) 6. 505-537.

Haugen, Einar. 1983. The implementation of corpus planning: Theory and practice. In: Juan Cobarrubias \& Joshua A. Fishman (eds.). Progress in language planning. International perspectives. The Hague: Mouton, 269-29o. (Contributions to the Sociology of Language, number 31).

Hu Changqing 胡長青. 1996. Xiān Qín fēnshù biǎoshìfã jí qí fāzhăn 先秦分数表示法 及其发展 [Expression and evolution of the pre-Qin expression of fractions]. Gǔhànyǔyánjiū 《古汉语研究》[Research in Ancient Chinese Language] (Changsha) 32. 45-48.

Li Yan 李儼. 1998. Lǔ Yăn Qián Băocóng kēxué shǔ quán ji 《李俨钱宝琮科学史全 集》[Complete works of Lǐ Yăn and Qián Băocóng on the history of sciences]. Shěnyáng: Liáoníng chūbǎnshè 辽宁出版社 [Liaoning Publishing Group] (10 volumes). 
Li Zhizao 李之藻. 18th century edition [1613]. Tóng wén suàn zhǐ 《同文算指》. (The 18th century edition belongs to the Si kù quán shū 四庫全書 [Complete Library in Four Sections]).

Peng Hao 彭浩. 2001. Zhāngjiāshān Hàn jiăn «Suàn shù shū»zhùshi 《張家山漢 簡《算術書》注釋》[Commented edition of the Suàn shù shü, a book written on bamboo strips and excavated from a Han dynasty tomb at Zhāngjiāshān]. Běijīng 北京: Kēxué chūbănshè科學出版社 [Science Press].

Peyraube, Alain 貝羅貝. 1998. Shànggǔ, zhōnggǔ hànyǔ liàngcí de lìshǐ fāzhăn 上古、 中古汉语量词的历史发展 [Historical evolution of classifiers in ancient Chinese]. Yǔyánxué lùncóng 《語言學論叢》[Collection on Linguistics] (Beijing) 21. 99-122.

Peyraube, Alain \& Thekla Wiebusch. 1993. Le rôle des classificateurs nominaux en chinois et leur évolution historique : un cas de changement cyclique. Faits de langues (Paris) 2. 51-61.

Qin Jiushao 秦九韶. 1842 [1247]. Shù shū jiǔ zhāng 《數書九章》.

Shi Yuechun 时曰醇. 1872 [1861]. Bǎi jū shùyăn 《百鸡术衍》. (The 1872 edition belongs to the Báifú táng suàn xué cóng shū 《白芙堂算學叢書》collection).

Tian Youcheng 田有成 \& Zeng Luping 曾鹿平. 2000. Jìndài hànyǔ shùcí biǎoshì fă 近代汉语数词表示法 [The numeral expressions of Modern Chinese]. Yán'ān Dàxué xuébào (shèhuì kêxué băn) 《延安大学学报 (社会科学版)》[Journal of Yan'an University (Social Science)] (Yan'an) 22(3). 99-101.

United Nations Chinese website. Accessed May 18, 2014. http://www.un.org/chinese/ millenniumgoals/unsystem/indicator3.htm.

Wu Jiashan 吳嘉善. 1874 [1863]. Suàn xué èr shíyīzhǒng《算學二十一種》. (The 1874 edition belongs to the Bái fú táng suàn xué cóng shū 《白芙堂算學叢書》collection.)

Wu Wenjun 吳文俊 (ed.). 2000. Qìng zhōng qĩ dào qīng mò 《清中期到清末》[The Qing dynasty, from the 18th century to the end]. Běijīng 北京: Běijīng shīfàn dàxué chūbǎnshè 北京師範大學出版社 [Beijing Normal University Publishing Group]. (Zhōngguó shùxué shù dàxì 《中國數學史大系》[Complete Series on the History of Chinese Mathematics]; 8)

Xiao Can 当橴 2010. Yuèlù Shūyuàn cáng Qín jiăn Shù yánjiū 获麓書院藏秦 簡《數》研究 [Study of Shù, A Qin dynasty text written on bamboo strips and kept at the Yuèlù Academy]. PhD dissertation: Hunan University)

Xiao Congli 肖從禮. 2006. Dūnhuáng, Jūyán Hàn jiăn zhōng de shùcí hé shùliàng biǎoshì fă 敦煌、居延汉简中的数词和数量表示法 [Expression of numerals and quantity in Han texts on bamboo strips found in Dunhuang and Juyan]. Dūnhuáng xuéjí kān 《敦煌学辑刊》 [Journal of Dunhuang Studies] (Lanzhou) 53.58-66.

Xiǎoxué Shùxué Liù Niánjí Shàng Cè 《小学数学六年级上册》[Sixth Grade Textbook of Mathematics - First Book]. 20o6. Beijing: Rénmín Jiàoyù Chūbănshè 人民教育 出版社 [People's Education Press]. 
Zhang Shoujun 張守軍. 1997. Gǔdài hànyǔ shùliàngcì shryyòng fāngfă 古代汉语数量 伺使用方法 [Use of quantifiers in Old Chinese]. Liáoníng guăngbō diànshi dàxué xuébào 《辽宁广播电视大学学报》[Academic Journal of the Radio and Television University of Liaoning] (Shenyang) 2. 77-81.

Zhōngguó shèhuì kēxuéyuàn kăogǔ yánjiūsuǒ 中國社會科學院考古研究所 (ed.). 1984. Yìn-Zhōu jīnwén jíchéng 《殷周金文集成》. Shanghai: Zhōnghuá shūjú 中華 書局 [Zhonghua Book Company]. 